5. Shibata S, Tada Y, Asano Y, Hau CS, Kato T, Saeki H, et al. Adiponectin regulates cutaneous wound healing by promoting keratinocyte proliferation and migration via the ERK signaling pathway. J Immunol 2012;189:3231-3241.

6. Salathia NS, Shi J, Zhang J, Glynne RJ. An in vivo screen of secreted proteins identifies adiponectin as a regulator of murine cutaneous wound healing. J Invest Dermatol 2013; 133:812-821.
7. Hsu S, Dickinson D, Borke J, Walsh DS, Wood J, Qin H, et al. Green tea polyphenol induces caspase 14 in epidermal keratinocytes via MAPK pathways and reduces psoriasiform lesions in the flaky skin mouse model. Exp Dermatol 2007; 16:678-684.

8. Jin T, Park KY, Seo SJ. Adiponectin upregulates filaggrin expression via SIRT1-mediated signaling in human normal keratinocytes. Ann Dermatol 2017;29:407-413.

\title{
A Case of Suggested Pigmented Condyloma Acuminatum
}

\author{
Ji Hong Lim, Yu Ri Woo, Miri Kim, Hyun Jeong Park \\ Department of Dermatology, Yeouido St. Mary's Hospital, College of Medicine, The Catholic University of Korea, Seoul, Korea
}

\section{Dear Editor:}

Human papillomavirus (HPV) infection of the genital skin is highly prevalent and showed variable presentations. Low-risk HPV type 6 or 11 is usually detected in cases of condyloma acuminatum (CA), while high-risk HPV type 16 or 18 is detected in cases of bowenoid papulosis (BP) ${ }^{1}$. Expression of $\mathrm{p} 16$ protein ( $\mathrm{p} 16$ ) has also been identified as a marker for HPV infection and is typically associated with neoplasia of the genital lesion ${ }^{2}$.

We received the patient's consent form about publishing all photographic materials. A 29-year-old male patient presented with multiple brownish verrucous papules on his penis that had been present for 1 year and had been pro-

Received May 10, 2018, Revised June 5, 2018, Accepted for publication June 20, 2018

Corresponding author: Hyun Jeong Park, Department of Dermatology, Yeouido St. Mary's Hospital, College of Medicine, The Catholic University of Korea, 10 63-ro, Yeongdeungpo-gu, Seoul 07345, Korea. Tel: 82-2-3779-1230, Fax: 82-2-783-7604, E-mail: hjpark@catholic.ac.kr ORCID: https://orcid.org/0000-0002-0138-9885

This is an Open Access article distributed under the terms of the Creative Commons Attribution Non-Commercial License (http://creativecommons. org/licenses/by-nc/4.0) which permits unrestricted non-commercial use, distribution, and reproduction in any medium, provided the original work is properly cited.

Copyright (c) The Korean Dermatological Association and The Korean Society for Investigative Dermatology gressively increasing in size. He had no subjective symptoms including pruritus or pain. He had no family or personal history of skin cancer or other medical diseases. Physical examination revealed multiple, $0.7 \times 0.8 \mathrm{~cm}$ sized brownish verrucous papules around the penile shaft (Fig. 1). Histopathological examination revealed parakeratosis, acanthosis, papillomatosis, vacuolated keratinocytes and a slightly disordered arrangement of keratinocytes without atypia throughout the thickened epidermis (Fig. 2A, B). Focal positive p16 expression was present in the lesion (Fig. 2C). HPV DNA chip $^{\mathrm{TM}}$ microarray analysis
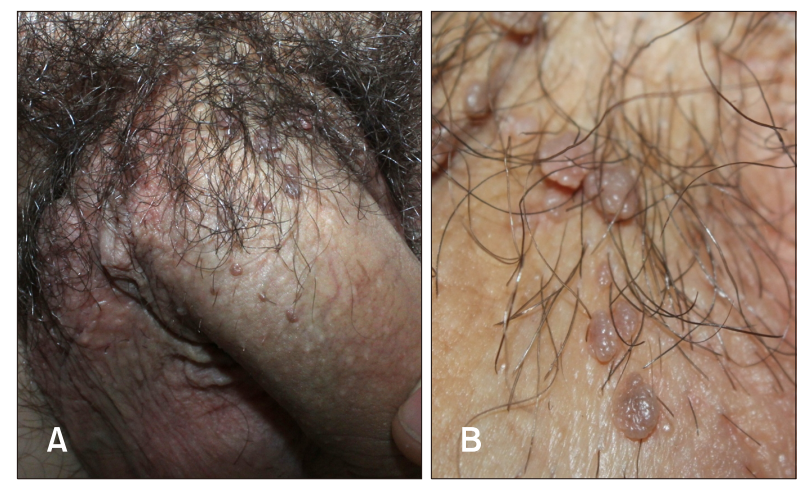

Fig. 1. (A, B) Multiple, $0.7 \times 0.8 \mathrm{~cm}$ brownish verrucous papules around the penis shaft. 

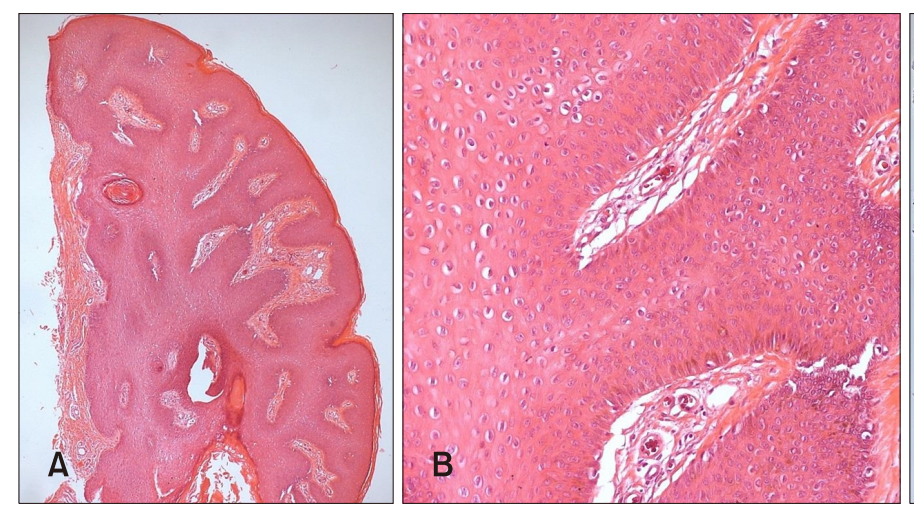

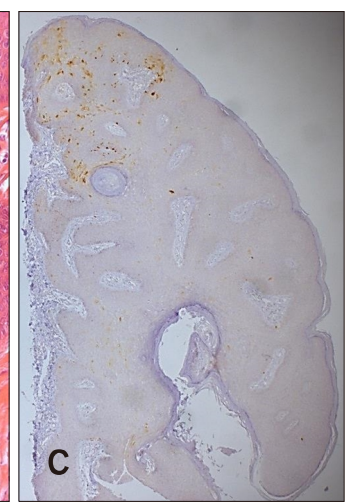

Fig. 2. Histopathological examination revealed parakeratosis, acanthosis, papillomatosis, vacuolated keratinocytes and a slightly disordered arrangement of keratinocytes without throughout the thickened epidermis. Focal positive p16 expression in the lesion $(\mathrm{A}: \mathrm{H} \& \mathrm{E}$, $\times 40$; B: H\&E, $\times 200$; C: $116, \times 40)$.
(My Gene Co., Seoul, Korea) was used for HPV genotyping and HPV-6 was identified from DNA extracted from the lesion. Based on these findings, a diagnosis of suggested pigmented CA was made. The lesion was successfully treated with electroablation. Follow-up over 1 year showed no recurrence of the lesions.

Clinically, it is difficult to distinguish CA from BP and Bowen's disease when CA exhibits pigmentation ${ }^{3}$. Although BP and CA are infectious disease caused by HPV, BP is caused by HPV 16 and 18 and histologically, BP resembles Bowen's disease. In Bowen's disease, atypical squamous cells proliferate through the whole thickness of the epidermis. HPV typing is helpful in gaining a better understanding of the relationship between clinical findings and HPV genotypes.

Kazlouskaya et al. ${ }^{4}$ reported that while 24 patients with CA showed sporadic and focal positive staining for $\mathrm{p} 16$, 12 patients with BP exhibited diffuse staining for $\mathrm{p} 16$. Consistent with the prior study, this case also showed a focal positive pattern for p16 stain. The exact mechanism of pathogenesis for pigmented CA remains unclear. Although Shimizu et al. ${ }^{5}$ speculated that a variety of HPV strains may induce melanogenesis ${ }^{5}$, more comprehensive study is needed to explain pathways affecting pigmentation in CA. As far as it is possible to determine, there have been no cases of pigmented CA in the Korean literature. Herein, is reported a rare and interesting case of a patient with suggested pigmented CA. Due to the difficulty of making the clinical diagnosis between pigmented CA, BP and Bowen's disease in certain cases, HPV DNA chip microarray and pattern of p16 staining are helpful for distinguishing pigmented CA from other disorders.

\section{ACKNOWLEDGMENT}

This research was supported by the Basic Science Research program and Creative Materials Discovery Program through the National Research Foundation of Korea (NRF), which is funded by the Ministry of Education, Science and Technology and the Ministry of Science, ICT and Future Planning (2015R1C1A2A01055073, 2016M3D1A1021387).

\section{CONFLICTS OF INTEREST}

The authors have nothing to disclose.

\section{ORCID}

Ji Hong Lim, https://orcid.org/0000-0002-3353-5795

Yu Ri Woo, https://orcid.org/0000-0003-2903-9534

Miri Kim, https://orcid.org/0000-0001-5167-3449

Hyun Jeong Park, https://orcid.org/0000-0002-0138-9885

\section{REFERENCES}

1. Park KC, Jung SY, Choi YM, Kim SH, Lee YS. Detection of genital human papilloma viruses using PCR. Ann Dermatol 1991;3:37-39.

2. Sano T, Oyama T, Kashiwabara K, Fukuda T, Nakajima T. Expression status of $\mathrm{p} 16$ protein is associated with human papillomavirus oncogenic potential in cervical and genital lesions. Am J Pathol 1998;153:1741-1748.

3. Shimizu A, Tamura A, Nakatani Y, Shimizu N, Hoshino H, Ishikawa O. Pigmented plaque-type condyloma acuminatum associated with human papillomavirus type 6. J Dermatol 2012;39:860-861.

4. Kazlouskaya V, Shustef E, Allam SH, Lal K, Elston D. Expression of p16 protein in lesional and perilesional condyloma acuminata and bowenoid papulosis: clinical significance and diagnostic implications. J Am Acad Dermatol 2013;69:444-449.

5. Shimizu A, Kato M, Ishikawa O. Pigmented condyloma acuminatum. J Dermatol 2014;41:337-339. 